\title{
REPORT OF THE COMMITTEE ON NOMENCLATURE AND NOTATION.*
}

To the President and Members of the American Chemical SOCIETY :

Gentlemen: Your Committee, appointed to consider a system of nomenclature and notation, to be used in the publications of the Society, beg leave to submit the following report:

Recognizing the importance of uniform practice in respect to nomenclature and notation among chemists speaking the same language, your Committee have felt that none but the most weighty considerations would warrant any serious departure from the system already established by the English Chemical Society $\dagger$ (Jour. Chem. Soc. 41, 24\%). While there are minor points in that system which do not meet with their full approval, it has been thought best, on the whole, to recommend its adoption as it now stands, subject only to the following modifications and additions, which relate only to minor points and will not interfere with the use of the system as a whole. The numbers nsed below refer to the sections of the system published.

1. Instead of "sodium methoxide," "ethoxide," etc., for the compounds $\mathrm{CH}_{3} \mathrm{ONa}$, etc., say sodium-methyl oxide, etc.

6. Call all ethers (see section 8 ) by names indicating the constituent radicals, e. g., say phenolmethyl ether, etc., for $\mathrm{C}_{6} \mathrm{H}_{6}-\mathrm{O}$ $-\mathrm{CH}_{3}$, etc., not "anisoil," etc.

Indicate the number of molecules of hydroxyl in alcohols by calling them univalent, bivalent, ete., not "mono-hydrie," "di-hydric," etc.

11-12. Unnecessary spreading of formulæ should be avoided for the sake of convenience in printing. Structural formulæ occupying more than a single line, vertically, should be used only when required for demonstration.

In all dissected formulæs use dashes, not dots, for bonding of elements. Avoid the use of the symbols $\mathrm{Et}, \mathrm{Me}$, etc., in formulæ. Write the formula of the radical in full.

* Adopted at the regular meeting June 4, 1886.

$\dagger A$ copy of the system is appended to this report. 
ADDITIONAL SUGGESTIONS.

Use the words nitrating to describe the introduction of $\mathrm{NO}_{2}$ into a compound. Nitrosing to indicate insertion of NO, and nitrizing or azotizing for the process of introducing $(-\mathrm{N}=\mathrm{N}-)$, as in the azo-compounds.

Use the term ester, generically, to denote the salts of the alcohol radicals, $\mathrm{C}_{2} \mathrm{H}_{5} \mathrm{NO}_{3}$, etc., instead of the term "compound ether." Also use the term ester acid for the class of acids represented by $\mathrm{C}_{2} \mathrm{H}_{5} \mathrm{HSO}_{4}$, etc.

Use the terms aluminium and boric acid, and the symbols $\mathrm{B}, \mathrm{P}$ and F, instead of "aluminum," "boracic acid," $\mathrm{Bo}, \mathrm{Ph}, \mathrm{Fl}$.

In advising the adoption of the system here given, it is admitted that the principles which it embodies are merely for general guidance, and that many cases may arise, especially in the literature of investigation, in which they will be found to be inadequate or to hamper the expression of an author's views. In such cases the author should be allowed the widest liberty that is consistent with clearness of expression. It is more important that the vocabulary of a purely technical literature should be flexible and comprehensive than that it should be simple. On the other hand, the demands of teaching and the needs of those engaged in related branches of science, or in commerce, direct that chemical nomenclature should be sufficiently fixed and definite to render the subject of chemistry accessible to those who are less acquainted with its technical details. It is believed that this end will be as well served by the plan in question as by any that could now be adopted.

The present aspect of chemistry is such that a system of nomenclature that shall be at once comprehensive and permanent is practically unattainable, and in view of the world-wide assent and cooperation which must be secured before any decided change in existing methods can be brought about, your committee do not feel that it falls within their province, at this time, to cffer any general plan for the improvement of chemical nomenclature.

It is suggested, however, that the inadequacy of existing methods is in marked contrast with that which obtains in the nomenclature of other branches of science, and in view of the fact that chemistry is adapted above these latter to the application of a strictly scientific system in this respect, it may well be asked whether the whole 


\title{
118 REPORT OF COMMITTEE ON NOMENCLATURE AND NOTATION.
}

subject of nomenclature should not be considered anew by chemists, with a view to the introduction of radical changes at an early day. In such a movement, this Society would, doubtless, be glad to assist.

The recent suggestion of Dr. Odling in regard to the desirability of introducing new empirica! names, as bases or starting points in the construction of chemical names, especially in the field of organic chemistry (Chem. Nex: 52, 181, et st $\%$ ), is warmly seconded by your committee as one which promises a measure of relief from the confusion which now threatens chemical nomenclature. His other suggestions, especially as they relate to the amendment of the system already recommended in this report, have also been considered. It is believed, however, with regard to these latter that, if adopted, they can only be adopted as part of a more extended series of changes in nomenclature than can at present be advised.

Your committee would also suggest that much improvement in nomenclature would result from the introduction of a limited number of new terminations to be used generically. Such terminations, however, to be useful and acceptable must be euphonious and etymologically correct. The recent suggestion of scheibler (Ber. 18, $6.4 j)$, in regard to the terminations -rse and -biose in the nomenclature of sugars of the glucose and saccharose classes respectively, is a step in the direction of the above suggestion.

In view of the importance of the subject and the delicacy of questions which are likely to arise in connection with it, it is suggested, in conclusion, that a committee on nomenclature and notation be added to the list of the standing committees of this Society.

\author{
A. A. Breneman, \\ G. E. MoORE, \\ A. R. LEEDS, \\ James H. Stebbins, JR., \\ WM RuPP,
}

